\title{
An Assessment of Whole Blood and Fractions by Nested PCR as a DNA Source for Diagnosing Canine Ehrlichiosis and Anaplasmosis
}

\author{
Tereza Emmanuelle de Farias Rotondano, ${ }^{1}$ Alzira Maria Paiva de Almeida, ${ }^{2}$ \\ Elane Maria Camboim Lustosa, ${ }^{3}$ Aline Antas Cordeiro, ${ }^{3}$ \\ Expedito Kennedy Alves Camboim, ${ }^{3}$ Sérgio Santos de Azevedo, ${ }^{3}$ \\ Paulo Paes de Andrade, ${ }^{4}$ and Marcia Almeida de Melo $^{3}$ \\ ${ }^{1}$ Departamento de Ciências Biológicas, Universidade Federal de Pernambuco, Avenue Professor Moraes Rego, s/n, \\ Cidade Universitária, 50.670-901 Recife, PE, Brazil \\ ${ }^{2}$ Centro de Pesquisas Aggeu Magalhães, FIOCRUZ-PE, Avenue Professor Moraes Rego, s/n, Cidade Universitária, \\ 50.670-901 Recife, PE, Brazil \\ ${ }^{3}$ Unidade Acadêmica de Medicina Veterinária, Universidade Federal de Campina Grande, 58.700-970 Patos, PB, Brazil \\ ${ }^{4}$ Departamento de Genética, Universidade Federal de Pernambuco, Avenue Professor Moraes Rego, s/n, \\ Cidade Universitária, 50.670-901 Recife, PE, Brazil
}

Correspondence should be addressed to Marcia Almeida de Melo, marcia.melo@pq.cnpq.br

Received 23 June 2012; Accepted 12 July 2012

Academic Editors: B. Harrach and A. Reis

Copyright (C) 2012 Tereza Emmanuelle de Farias Rotondano et al. This is an open access article distributed under the Creative Commons Attribution License, which permits unrestricted use, distribution, and reproduction in any medium, provided the original work is properly cited.

\begin{abstract}
Ehrlichiosis and anaplasmosis are tick-borne diseases. Ehrlichia canis and Anaplasma platys infect mainly white cells and platelets, respectively. The main DNA source for PCR is peripheral blood, but the potential of blood cell fractions has not been extensively investigated. This study aims at assessment of whole blood (WB) and blood fractions potential in nested PCR (nPCR) to diagnose canine ehrlichiosis and anaplasmosis. The $16 \mathrm{~S}$ rRNA gene was amplified in 71.4, 17.8, 31.57, and 30\% of the WB, granulocyte (G), mononuclear cells (M), and buffy coat (BC) samples. Compared to the WB, the sensitivity of the PCR was $42.86 \%$ for the M, and BC fractions, $21.43 \%$ for the G, and $33.33 \%$ for the blood clot (C). There was fair agreement between the WB and M, BC and C, and slight with the G. Fair agreement occurred between the nPCR and morulae in the blood smear. One animal was coinfected with A. platys and E. canis. This study provided the first evidence of A. platys infection in dogs in Paraíba, Brazil, and demonstrated that WB is a better DNA source than blood fractions to detect Ehrlichia and Anaplasma by nPCR, probably because of the plasma bacterial concentration following host cell lysis.
\end{abstract}

\section{Introduction}

Ehrlichiosis and anaplasmosis are important, emerging zoonotic tick-borne diseases caused by gram-negative, obligate intracellular bacteria from the Anaplasmataceae family. In the host cells, the bacteria reside in inclusion bodies (morulae), which provide a hospitable environment for survival $[1,2]$.

Canidae can be infected by several Anaplasmataceae agents: Ehrlichia canis, E. ewingii, E. chaffeensis, Anaplasma platys, A. phagocytophilum, Neorickettsia risticii, and $N$. helminthoeca. Ehrlichia and Anaplasma infections are transmitted through the salivary secretions of attached ticks. Ehrlichia canis is usually transmitted by brown dog tick (Rhipicephalus sanguineus) bites, which can also transmit E. ewingii and most likely Anaplasma platys [1]. The occurrence of the tick $R$. sanguineus parasitizing humans in Brazil [3] serves to warn the risk of transmission of such pathogens $(A$. platys and E. canis) to humans $[4,5]$.

E. canis species mainly infect monocytes, which causes canine monocytic ehrlichiosis, and A. platys species infect platelets, which causes canine cyclic thrombocytopenia. 
The A. platys platelet tropism is unique among ehrlichialrelated organisms, even though all of these infections may result in thrombocytopenia [2]. E. canis is the main pathogen implicated in cases of canine ehrlichiosis in Brazil, but $A$. platys has recently been identified by PCR in samples from the South region with a prevalence ranging from $25.5 \%$ to $55 \%[1,5]$.

The diagnosis of canine ehrlichiosis and anaplasmosis relies on the cultivation, serology, PCR, and direct microscopic examination of stained blood smears to identify intracytoplasmic morulae. Smear diagnosis has low sensitivity, as there are few bacteria present in the samples, morulae can be visualized only during the acute phase, and the percentage of infected cells is usually less than $1 \%$ [6]. Additionally, the presence of A. platys is cyclical, and the bacteria are easily mistaken as nonspecific inclusion bodies and staining artifacts $[1,7]$. Serology is hampered by cross-reactions and cannot discriminate between a current infection and previous exposure to the pathogen. Moreover, antibody titers tend to persist for several months to years after treatment, making serology an unreliable tool for posttreatment diagnosis [8].

The first PCR-based diagnostic method for ehrlichiosis amplified the 16S rRNA gene and was reported by Iqbal et al. in 1994 [9]. Further improvements and the use of other target genes increased the sensitivity of the tests. The p30based nested PCR (nPCR) assay has been shown to be more sensitive than the 16S rRNA-based nPCR assay [10], possibly because E. canis contains multiple copies of the p30 gene but only one copy of the 16S rRNA gene [11]. As opposed to single-step PCR, nPCR amplification of the 16S rRNA gene has been used more often to detect E. canis and A. platys. In both single step PCR and nPCR, the peripheral blood is frequently used as a DNA source $[1,5,12]$. Only a single report has described the use of mononuclear cells as a DNA source [9].

There is a high prevalence of canine ehrlichiosis, but there are few reports on the identification of the infectious agents; therefore, a practical diagnostic technique that can be routinely used in veterinary medicine must be established. The nPCR assay may fulfill this requirement, but the blood fraction that serves as the best DNA source must be determined beforehand. The aim of the present study was to compare the effectiveness of whole blood (WB) and blood fractions-buffy coat (BC), granulocytes (G), mononuclear fraction (M) and blood clot (C) - by nPCR to diagnose canine ehrlichiosis and anaplasmosis.

\section{Methods}

2.1. Samples and Cell Fractionation. Blood was collected from 21 dogs bearing suggestive clinical signs of either ehrlichiosis or anaplasmosis (petechia, ecchymosis, fever, and anorexia) and harboring ticks. Some animals also had intracytoplasmic morulae, as indicated by direct examination of blood smears and/or hematological parameters suggestive of ehrlichiosis and anaplasmosis. The dogs were selected from the veterinary hospital Universidade Federal de Campina Grande (UFCG), the Veterinary Medical Center Dr. Leonardo Torres at Patos, State of Paraiba, and at the Veterinary Hospital at Universidade Federal Rural de Pernambuco (UFRPE), at Recife, State of Pernambuco.

\subsection{Hematology, Direct Examination of Blood Smears and Cell} Fractionation. Routine platelet counts, packed cell volume, and other hematology parameters were performed at the hospitals referred to above. The reference values were those described in Jain (1993) [15]. WB smears were stained with a hematoxylin-eosin-based rapid stain (Panótico rápido, Laborclin, Brazil) and observed by microscopy (100X objective, under immersion oil). The M- and G-enriched samples were obtained from $4 \mathrm{~mL}$ of WB with the SepCell kit (LGC Biotecnologia, Brazil), according to the manufacturer's instructions. The BC fraction was collected from $1 \mathrm{~mL}$ blood that was centrifuged at $12,000 \mathrm{~g}$ for $10 \mathrm{~min}$.

2.3. DNA Extraction. From each dog, a sample of blood was collected, and the DNA was extracted. Four milliliters of blood were extracted with sodium citrate and $1 \mathrm{~mL}$ without sodium citrate. The DNA samples from the WB $(200 \mu \mathrm{L}), \mathrm{BC}$ $(50 \mu \mathrm{L}), \mathrm{M}(50 \mu \mathrm{L}), \mathrm{G}(100 \mu \mathrm{L})$, and $\mathrm{C}(50 \mu \mathrm{L})$ fractions were extracted with a commercial kit (Invisorb Spin Blood Midi kit; INVITEK), following the manufacturer's instructions. The DNA from $21 \mathrm{WB}, 19 \mathrm{G}$ and $19 \mathrm{M}, 20 \mathrm{BC}$, and $15 \mathrm{C}$ samples was used in the nPCR to amplify the E. canis and A. platys 16S rRNA sequences.

2.4. Nested PCR (nPCR). The first round of PCR used 0.5 to $1.0 \mu \mathrm{g}$ of the genomic DNA, and the primers ECC and ECB were designed to amplify a 478 base-pair (bp) fragment of the Ehrlichia 16S rRNA [13]. The second round of PCR used a $1.0 \mu \mathrm{L}$ aliquot of the first reaction as a template and the EHCA sense/EHCA antisense [14] and EHPL sense/EHPL antisense (João Pessoa Araújo Jr.: pers. comm., 2010) primers, which were designed to amplify a $389 \mathrm{bp}$ fragment for $E$. canis and $384 \mathrm{bp}$ fragment for $A$. platys, respectively. Separate reactions were used to detect each species individually. The primers are described in Table 1 . The primer design was confirmed with the software Primer 3 (http://fokker.wi.mit.edu/primer3/input.htm). The reaction mix contained $1 \mathrm{X}$ reaction buffer $(50 \mathrm{mM} \mathrm{KCl}$, $20 \mathrm{mM}$ Tris- $\mathrm{HCl}$ (pH 8.4), and 0.1\% Triton X-100), $1.75 \mathrm{mM}$ $\mathrm{MgCl}_{2}, 0.2 \mathrm{mM}$ dNTP mix, $1 \mu \mathrm{M}$ PCR primers, $0.625 \mathrm{U}$ Taq DNA polymerase, and autoclaved ultrapure water to a final volume of $25 \mu \mathrm{L}$. The thermocycle was as follows: $94^{\circ} \mathrm{C}$ for 10 minutes followed by 40 cycles at $94^{\circ} \mathrm{C}$ for 60 seconds, $60^{\circ} \mathrm{C}$ for 60 seconds, $72^{\circ} \mathrm{C}$ for 60 seconds, and a final step of $72^{\circ} \mathrm{C}$ for 4 minutes before holding at $4^{\circ} \mathrm{C}$. Ultra-pure autoclaved water was used as negative control in each PCR batch. The genomic DNA from confirmed E. canis and A. platys cases was used as positive controls for the E. canis 16S rRNA and $A$. platys $16 \mathrm{~S}$ rRNA genes, respectively. Ten microliters of the final products were electrophoresed at 90 volts for approximately 1 hour in 1.5\% agarose gels containing ethidium bromide in Tris-Borate EDTA (TBE). 
TABLE 1: The primer sequences for the $16 \mathrm{~S}$ rRNA gene used to detect the E. canis and A. platys by the nPCR reactions.

\begin{tabular}{|c|c|c|c|c|c|}
\hline $\begin{array}{l}\text { Primer } \\
\text { identification }\end{array}$ & $\begin{array}{c}\text { Etiological } \\
\text { agent }\end{array}$ & Primer sequences & Reference & $\begin{array}{l}\text { Expected amplified } \\
\text { segment length }\end{array}$ & $\begin{array}{c}\text { From-to } \\
\text { (bp) }\end{array}$ \\
\hline ECC & E. spp. & AGAACGAACGCTGGCGGCAAGCC & \multirow{2}{*}{ Dawson et al. [13] } & \multirow{2}{*}{478 bp } & \multirow{2}{*}{$13-490$} \\
\hline ECB & E. spp. & CGTATTACCGCGGCTGCTGGC & & & \\
\hline EHCA sense & E. canis & CAATTATTTATAGCCTCTGGCTATAGC & \multirow{2}{*}{ Wen et al. [14] } & \multirow{2}{*}{389 bp } & \multirow{2}{*}{$58-446$} \\
\hline EHCA antisense & E. canis & TATAGGTACCGTCATTATCTTCCCTAT & & & \\
\hline EHPL sense & A. platys & TTTTTGTCGTAGCTTGCTATGATA & \multirow{2}{*}{$\begin{array}{l}\text { João Pessoa Araújo Jr., } \\
\text { pers. comm }\end{array}$} & \multirow{2}{*}{$384 \mathrm{bp}$} & \multirow{2}{*}{$49-432$} \\
\hline EHPL antisense & A. platys & TGTGGGTACCGTCATTATCTTCCCCA & & & \\
\hline
\end{tabular}

The E. canis and A. platys reactions were positive when a 389 or a 384 bp fragment was detected, respectively.

2.5. Statistical Analysis. The kappa and related indices were calculated by Dag Stat software [16] to determine the agreement between the results for the WB (gold standard) and blood fractions. The McNemar test was used to evaluate the concordance among DNA sources, and the Fisher's exact test was used to determine the association between thrombocytopenia, anemia, and a positive WB nPCR. The significance level was 5\% for all of the analyses.

2.6. Ethical Considerations. The animals were used according to the guidelines of Oswaldo Cruz Foundation from Brazil's Ministry of Health.

\section{Results}

Table 2 shows the results of hematological, blood smear (direct examination), and $\mathrm{nPCR}$ on the $\mathrm{WB}, \mathrm{G}, \mathrm{M}, \mathrm{BC}$, and $\mathrm{C}$ samples from 21 dogs exhibiting clinical signs of ehrlichiosis. From each group, negative samples were detected. In seven animals (46.6\%), identification at species level failed, as there was no amplification in the second PCR. Among them, the blood smears of five dogs were positive by direct examination and two displayed cytoplasmic inclusions.

Seven dogs (33.3\%) were positive by nPCR and direct examination of blood smears (presence of morulae); inclusions within platelets were found in two blood smears. Out of the 14 blood smear-negative animals, eight (63.6\%) had at least one blood fraction positive for Ehrlichia or Anaplasma by nPCR, corresponding to $57.1 \%$ false negatives by direct examination. The WB DNA samples from $66.6 \%$ $(6 / 9)$ thrombocytopenic and $42.85 \%$ (3/7) anemic animals were positive by $\mathrm{nPCR}$.

Among $21 \mathrm{WB}$ samples, 26.6\% (6/21) were negative by nPCR, and 71.4\% (15/21) were positive: $46.4 \%$ (7/15) for $E$. canis (Figure 1) and 6.6\% (1/15) for A. platys. E. canis was identified in G samples from 1.8\% (3/19), in M samples from $31.6 \%(6 / 19)$, and in BC samples from $31.6 \%(6 / 19)$ animals. One BC sample was coinfected with E. canis and A. platys. Among the C samples, $7.14 \%$ (1/14) were positive for $E$. canis and $14.3 \%(2 / 14)$ for A. platys.

Among the nPCR assays carried out in all samples (WB, G, M, BC, and C) from 11 animals, at least 63.3\% (7/11) were

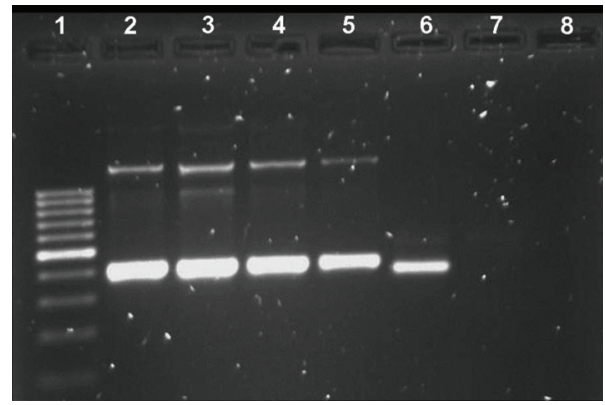

FIgURE 1: Detection of Ehrlichia canis in nPCR with EHCA sense and antisense primers for rRNA 16S gene. Lane 1: 100 base pair (bp) DNA ladder; lanes from 2 to 5: nPCR with DNA from WB; lane 6: $E$. canis-positive control and DNA from WB; lane 7: negative control; lane 8: nPCR-negative control.

positive; $\mathrm{WB}$ and $\mathrm{C}$ samples were simultaneously positive in $9 \%(1 / 11)$ and $\mathrm{WB}, \mathrm{M}$, and $\mathrm{BC}$ in $18.1 \%(2 / 11)$.

The nPCR sensitivity was $42.86 \%$ when the $\mathrm{WB}$ was compared to the $\mathrm{M}$ and $\mathrm{BC}$ fractions (McNemar test: $X^{2}=$ $6.13 ; P=0.013), 21.43 \%$ compared to the $G$ fraction (McNemar test: $X^{2}=9.09 ; P=0.003$ ), and $33.33 \%$ compared to the $\mathrm{C}$ fraction (McNemar test: $X^{2}=4.17 ; P=$ $0.041)$. The kappa value showed fair agreement among WB and $\mathrm{M}($ Kappa $=0.28), \mathrm{BC}($ Kappa $=0.31)$, and $\mathrm{C}$ fractions $($ Kappa $=0.26)$ and slight agreement with $\mathrm{G}$ fraction (Kappa $=0.13$ ). There was also fair agreement between the presence of morulae and the nPCR results (Kappa $=0.33$; McNemar test: $\left.X^{2}=6.13 ; P=0.0133\right)$.

\section{Discussion}

The direct examination of stained blood smears to detect Ehrlichia in dogs has a low sensitivity rate (3 to 9\%). In fact, E. canis morulae are difficult to detect in blood smears because this organism is usually present in very low concentrations [6]. In contrast, PCR has proven to be more sensitive for detecting Ehrlichia; for a $16 \mathrm{~S}$ rRNA-based PCR assay is able to detect E. canis DNA from a rickettsemia, which is equivalent to one infected monocyte in $10^{36}$ cells $[1,5,12]$. In addition to the large sensitivity differences inherent to the techniques, genotypic variants have been reported for E. ruminantium, and A. platys infects a wide range of host cells $[1,2,17]$. 


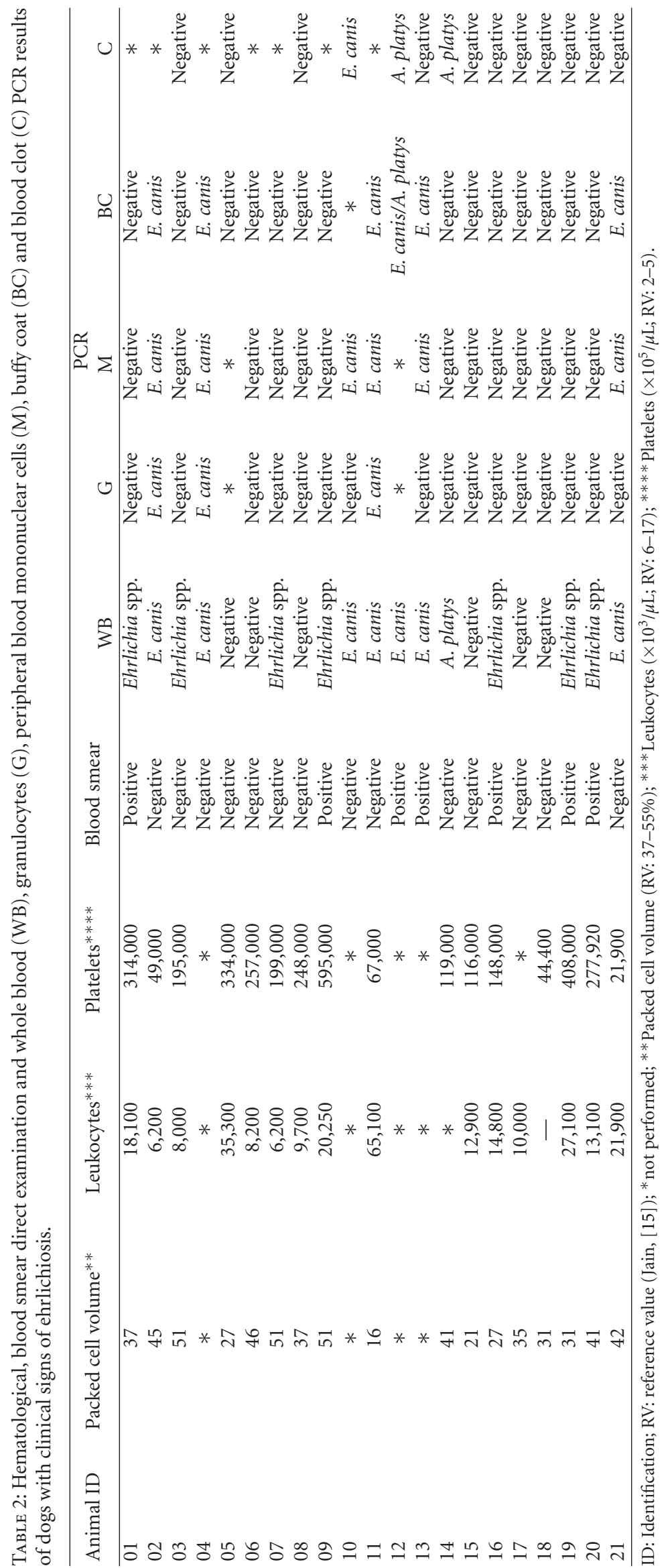


As expected, our study demonstrates that nPCR is more sensitive for detecting Ehrlichia than the direct examination of stained blood smears of dogs with suggestive clinical signs. Our results show that a $50 \%$ false negative rate may occur when only direct examination is used for diagnosis. In contrast, all animals with morulae in the blood smears were positive by $\mathrm{nPCR}$ for at least one of the WB or fraction samples.

The nPCR was able to detect Ehrlichia or Anaplasma DNA in $71 \%$ of the samples from dogs with suggestive clinical signs. This rate is slightly higher than that registered elsewhere in Brazil $[1,5,12]$. As previously reported $[1,5], E$. canis $(46.6 \%)$ positivity in WB was higher than for A. platys (6.6\%).

In seven $(46.6 \%)$ of the samples, there was no amplification in the second PCR, and the positives were recorded as Ehrlichia spp. As the primers used were specific for $E$. canis and A. platys, the presence of other Rickettsiales, such as A. phagocytophilum, E. chaffeensis, and E. ewingii, should not be disregarded because they can also form cytoplasmic inclusions [18, 19]. Furthermore E. ewingii was already reported in dogs in Brazil [20].

Coinfection with E. canis and A. platys was observed in an animal with a positive blood smear and that was positive for E. canis in the WB sample by nPCR. Cytoplasmic inclusions in the platelets were not observed, possibly due to low A. platys load [7]. It is worth mentioning that this is the first evidence for the involvement of A. platys in canine anaplasmosis in the State of Paraiba, Brazil.

The blood fraction samples that were positive for $A$. platys by nPCR were WB and C ( dog no. 14) and B and C (dog no. 12). Despite the small sample size, the results suggest an increased likelihood of finding A. platys DNA in the BC fraction, which is more enriched with platelets than the other samples.

Contrary to previous reports $[21,22]$, we found that there was no statistical association between thrombocytopenia $(P=0.596)$, anemia $(P=0.299)$, and the WB nPCR results. Similar to a previous report [1], anemia occurred in only $26.6 \%$ cases. These results demonstrate that thrombocytopenia is not sufficient to diagnose either canine ehrlichiosis or anaplasmosis. Santos et al. [22] also observed a high incidence of $E$. canis infection among nonthrombocytopenic dogs. In contrast, other diseases including immune-mediated thrombocytopenia, neoplasia, inflammatory diseases, or other infectious agents can provoke thrombocytopenia [23]. The differences in prevalence may reflect the diversity in strain pathogenicity or a selection bias because thrombocytopenic dogs are more likely to be tested for ehrlichiosis.

Peripheral blood has been the main source of Ehrlichia DNA for PCR assays because collection of this sample is less invasive than spleen and bone marrow collection. The use of serum samples for nPCR to detect E. canis has been suggested previously [24]. Our results support that whole blood is the best source for Ehrlichia DNA in PCR assays. Indeed, the Kappa value indicates a weak correlation between nPCR results from the WB samples and those obtained with the $\mathrm{G}, \mathrm{M}, \mathrm{BC}$, or $\mathrm{C}$ samples; the PCR sensitivity from the $\mathrm{M}$ and B samples was only $42.9 \%$. Therefore, our data and the literature support the use of WB as the best choice for DNA source for PCR Ehrlichia spp. detection.

This is the first assessment of the use of different blood cell fractions as DNA sources to diagnose canine ehrlichiosis and anaplasmosis by PCR. Although the pathogens only infect leukocytes and platelets, WB is a better DNA source than any of the cellular Ehrlichia-enriched host cell fractions. A possible explanation may be based on the assumption that WB samples contain not only intracellular Ehrlichia but also organisms released by host cell lysis that are not found in the fractions. In support of this hypothesis, the 16S rRNA gene was successfully amplified by Mylonakis et al. [25] by nPCR in sera samples from naturally infected dogs. Hence, these authors recommend serum-based PCR analysis for the early diagnosis of CME when WB samples are not available. Furthermore, it was demonstrated that $E$. chaffeensis reached concentrations of $\sim 10^{8}$ bacteria $/ \mathrm{mL}$ in the plasma of SCID mice two weeks after infection [26]. There are no similar studies for E. canis or A. platys, but it is reasonable to assume that a similar scenario occurs in dogs infected with these pathogens, especially in the acute phase of the disease, when symptoms are severe, and platelet counts are usually reduced.

In conclusion, the present study demonstrates that canine WB is better than other cellular blood fractions as a DNA source to detect Ehrlichia and Anaplasma by PCR, most likely because of the bacterial concentration in the plasma following host cell lysis.

\section{Conflict of Interests}

The authors declare that they have no conflict of interests.

\section{Acknowledgments}

This work was supported by the Brazilian National Research Council (CNPq) and by the State of Pernambuco Research Foundation (FACEPE). It was Financially supported by the Fundação de Amparo à Ciência e Tecnologia do Estado de Pernambuco (FACEPE). T. E. F. Rotondano was a FACEPE fellow during the development of this study. The authors thank the Laboratório de Diagnóstico Molecular (UNESP), Botucatu, SP, Brazil for testing the samples.

\section{References}

[1] A. S. Dagnone, A. I. Souza, M. R. André, and R. Z. Machado, "Molecular diagnosis of Anaplasmataceae organisms in dogs with clinical and microscopical signs of ehrlichiosis," Revista Brasileira de Parasitologia Veterinaria, vol. 18, no. 4, pp. 20-25, 2009.

[2] L. A. Cohn, "Ehrlichiosis and related infections," Veterinary Clinics of North America, vol. 33, no. 4, pp. 863-884, 2003.

[3] F. Dantas-Torres, L. A. Figueredo, and S. P. Brandão-Filho, "Rhipicephalus sanguineus (Acari: Ixodidae), the brown dog tick, parasitizing humans in Brazil," Revista da Sociedade Brasileira de Medicina Tropical, vol. 39, no. 1, pp. 64-67, 2006. 
[4] L. T. M. Figueiredo, S. J. Badra, L. E. Pereira, and M. P. J. Szabó, "Report on ticks collected in the Southeast and MidWest regions of Brazil: analyzing the potential transmission of tick-borne pathogens to man," Revista da Sociedade Brasileira de Medicina Tropical, vol. 32, no. 6, pp. 613-619, 1999.

[5] C. A. N. Ramos, R. A. N. Ramos, F. R. Araújo, D. S. Guedes Jr., and I. I. F. Souza, "Ono TM. Comparação de nested-PCR com o diagnóstico direto na detecção de Ehrlichia canis e Anaplasma platys em cães," Revista Brasileira De Parasitologia Veterinária, vol. 18, pp. 58-62, 2009.

[6] H. F. Cadman, P. J. Kelly, L. A. Matthewman, R. Zhou, and P. R. Mason, "Comparison of the dot-blot enzyme linked immunoassay with immunofluorescence for detecting antibodies to Ehrlichia canis," Veterinary Record, vol. 135, no. 15, p. 362, 1994.

[7] C. Arraga-Alvarado, M. Palmar, O. Parra, and P. Salas, "Ehrlichia platys (Anaplasma platys) in dogs from Maracaibo, Venezuela: an ultrastructural study of experimental and natural infections," Veterinary Pathology, vol. 40, no. 2, pp. 149156, 2003.

[8] T. Waner, S. Harrus, F. Jongejan, H. Bark, A. Keysary, and A. W. C. A. Cornelissen, "Significance of serological testing for ehrlichial diseases in dogs with special emphasis on the diagnosis of canine monocytic ehrlichiosis caused by Ehrlichia canis," Veterinary Parasitology, vol. 95, no. 1, pp. 1-15, 2001.

[9] Z. Iqbal, W. Chaichanasiriwithaya, and Y. Rikihisa, "Comparison of PCR with other tests for early diagnosis of canine ehrlichiosis," Journal of Clinical Microbiology, vol. 32, no. 7, pp. 1658-1662, 1994.

[10] R. W. Stich, Y. Rikihisa, S. A. Ewing, G. R. Needham, D. L. Grover, and S. Jittapalapong, "Detection of Ehrlichia canis in canine carrier blood and in individual experimentally infected ticks with a p30-based PCR assay," Journal of Clinical Microbiology, vol. 40, no. 2, pp. 540-546, 2002.

[11] S. Harrus and T. Waner, "Diagnosis of canine monocytotropic ehrlichiosis (Ehrlichia canis): an overview," Veterinary Journal, vol. 187, no. 3, pp. 292-296, 2011.

[12] A. C. H. Nakaghi, R. Z. Machado, M. R. André, C. D. Baldani, and M. T. Costa, "Canine ehrlichiosis: clinical, hematological, serological and molecular aspects," Ciencia Rural, vol. 38, no. 3, pp. 766-770, 2008.

[13] J. E. Dawson, D. E. Stallknecht, E. W. Howerth et al., "Susceptibility of white-tailed deer (Odocoileus virginianus) to infection with Ehrlichia chaffeensis, the etiologic agent of human ehrlichiosis," Journal of Clinical Microbiology, vol. 32, no. 11, pp. 2725-2728, 1994.

[14] B. Wen, Y. Rikihisa, J. M. Mott et al., "Comparison of nested PCR with immunofluorescent-antibody assay for detection of Ehrlichia canis infection in dogs treated with doxycycline," Journal of Clinical Microbiology, vol. 35, no. 7, pp. 1852-1855, 1997.

[15] N. C. Jain, Essentials of Veterinary Hematology, Lea \& Febiger, Philadelphia, Pa, USA, 1993.

[16] A. Mackinnon, "A spreadsheet for the calculation of comprehensive statistics for the assessment of diagnostic tests and inter-rater agreement," Computers in Biology and Medicine, vol. 30, no. 3, pp. 127-134, 2000.

[17] M. T. E. P. Allsopp and B. A. Allsopp, "Novel Ehrlichia genotype detected in dogs in South Africa," Journal of Clinical Microbiology, vol. 39, no. 11, pp. 4204-4207, 2001.

[18] R. F. Ferreira, A. M. F. Cerqueira, A. M. Pereira et al., " $A n-$ aplasma platys diagnosis in dogs: comparison between morphological and molecular tests," Journal of Applied Research in Veterinary Medicine, vol. 5, pp. 113-119, 2007.
[19] Y. Rikihisa, "Diagnosis of emerging ehrlichial diseases of dogs, horses, and humans," Journal of Veterinary Internal Medicine, vol. 14, no. 3, pp. 250-251, 2000.

[20] L. S. Oliveira, K. A. Oliveira, L. C. Mourão et al., "First report of Ehrlichia ewingii detected by molecular investigation in dogs from Brazil," Clinical Microbiology and Infection, vol. 15, no. 2, pp. 55-56, 2009.

[21] C. Bulla, R. K. Takahira, J. P. Araújo Jr., L. A. Trinca, R. S. Lopes, and C. E. Wiedmeyer, "The relationship between the degree of thrombocytopenia and infection with Ehrlichia canis in an endemic area," Veterinary Research, vol. 35, no. 1, pp. 141-146, 2004.

[22] F. Santos, J. S. Coppede, A. L. A. Pereira et al., "Molecular evaluation of the incidence of Ehrlichia canis, Anaplasma platys and Babesia spp. in dogs from Ribeirão Preto, Brazil," Veterinary Journal, vol. 179, no. 1, pp. 145-148, 2009.

[23] C. B. Grindem, E. B. Breitschwerdt, W. T. Corbett, and H. E. Jans, "Epidemiologic survey of thrombocytopenia in dogs: a report on 987 cases.," Veterinary Clinical Pathology, vol. 20, pp. 38-43, 2002.

[24] M. E. Mylonakis, V. I. Siarkou, L. Leontides, E. BourtziHatzopoulou, V. I. Kontos, and A. F. Koutinas, "Evaluation of a serum-based PCR assay for the diagnosis of canine monocytic ehrlichiosis," Veterinary Microbiology, vol. 138, no. 3-4, pp. 390-393, 2009.

[25] M. E. Mylonakis, A. F. Koutinas, C. Billinis et al., "Evaluation of cytology in the diagnosis of acute canine monocytic ehrlichiosis (Ehrlichia canis): a comparison between five methods," Veterinary Microbiology, vol. 91, no. 2-3, pp. 197-204, 2003.

[26] J. S. Li and G. M. Winslow, "Survival, replication, and antibody susceptibility of Ehrlichia chaffeensis outside of host cells," Infection and Immunity, vol. 71, no. 8, pp. 4229-4237, 2003. 

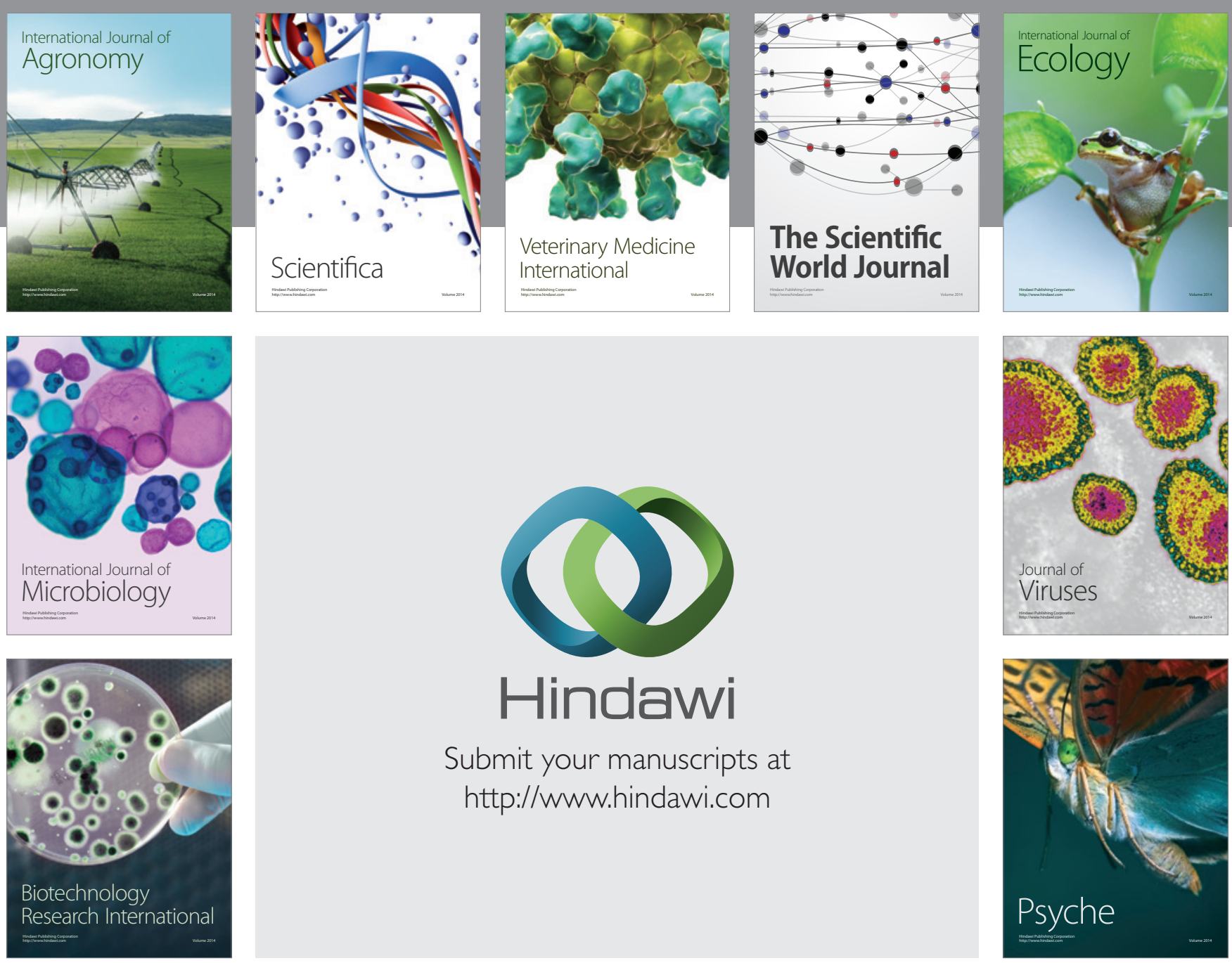

Submit your manuscripts at

http://www.hindawi.com
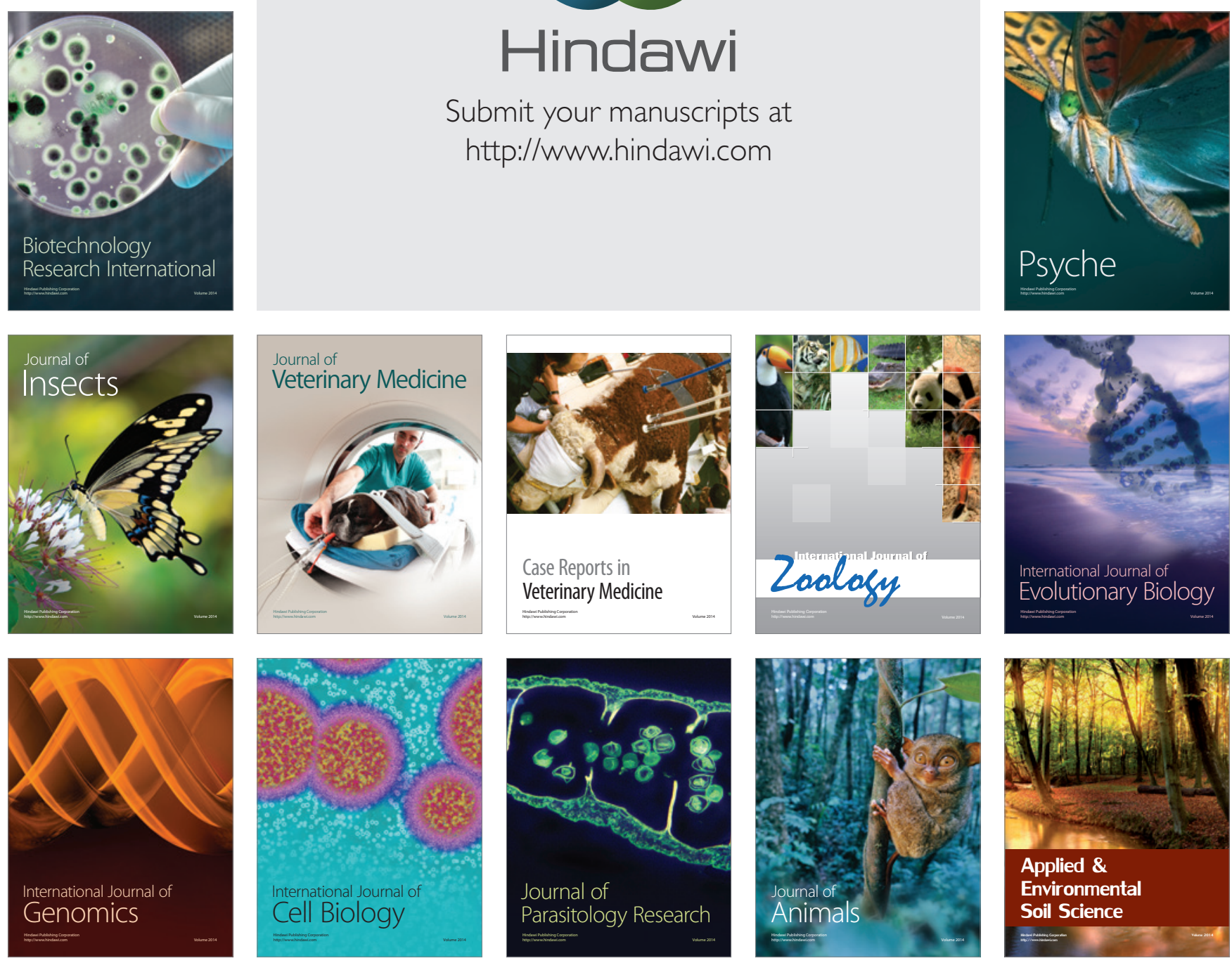